\title{
Structural and Optical Characterization of Ytterbium Doped Lutetium Double Phosphates ${ }^{1)}$
}

\author{
M. Guzik ${ }^{a}$, J. Legendziewicz ${ }^{a, *}$, W. Szuszkiewicz ${ }^{\text {b }}$, and A. Walasek ${ }^{a}$ \\ ${ }^{a}$ Wrocław/Poland, Faculty of Chemistry, University of Wrocław \\ ${ }^{\mathrm{b}}$ Wrocław/Poland, Institute of Chemistry of the Wroclaw University of Economics
}

Received August 7th, 2006.

\begin{abstract}
Powder samples of the ternary phosphates $\mathrm{A}_{3} \mathrm{Lu}\left(\mathrm{PO}_{4}\right)_{2}: \mathrm{Yb}^{3+}(\mathrm{A}=\mathrm{Na}, \mathrm{Rb})$ have been synthesised by solid state reactions. The spectroscopic properties of $\mathrm{Yb}^{3+}$ in double phosphate host lattices were investigated using absorption, emission and excitation spectra at 4,10 and $293 \mathrm{~K}$ in the VUV to IR range. The results obtained for both types of phosphates are compared. Together with the fundamental ${ }^{2} \mathrm{~F}_{5 / 2} \rightarrow{ }^{2} \mathrm{~F}_{7 / 2}$ emission in the IR range, a broad band emission with two peaks in the UV region
\end{abstract}

were observed in $\mathrm{Yb}^{3+}$-activated $\mathrm{Na}_{3} \mathrm{Lu}\left(\mathrm{PO}_{4}\right)_{2}$. The second emission is due to a charge-transfer transition type. The influence of the alkali metal cation site of the host lattice on the luminescence properties was investigated. The tentative energy level scheme of the ground and excited ${ }^{2} \mathrm{~F}_{\mathrm{J}}(\mathrm{J}=7 / 2,5 / 2)$ levels is described.

Keywords: Charge transfer emission; Lutetium double phosphates; doped $\mathrm{Yb}^{3+}$ ion
Compounds containing $\mathrm{Yb}^{3+}$ ions have potential applications as laser devices because of their simple electronic structure. There is no concentration quenching and no excited state absorption reducing the effective laser crossrelaxation process. The $\mathrm{Yb}^{3+}$ ion exhibits intense and broad absorption bands in the IR region which is suitable for a diode-pumped laser. It was reported that ytterbium-doped lasers have longer emission lifetimes than the $\mathrm{Nd}^{3+}$-doped materials. All these properties of $\mathrm{Yb}^{3+}$ indicate that the ytterbium-doped materials seem to be more promising than the neodymium-doped systems, already employed in laser materials. The fundamental luminescence of the $\mathrm{Yb}^{3+}$ ion originating from the ${ }^{2} \mathrm{~F}_{5 / 2} \rightarrow{ }^{2} \mathrm{~F}_{7 / 2}$ transitions between the manifold of Stark-splitted levels occur in the IR range around $1000 \mathrm{~nm}$.

While searching for interesting laser host materials for solid state lasers, alkali rare-earth double phosphates of the $\mathrm{M}_{3} \mathrm{RE}\left(\mathrm{PO}_{4}\right)_{2}$ type were studied by several authors [1-10]. These compounds have their host absorption edge at a rather short wavelength which makes them suitable as host lattices for various luminescent materials.

In addition to the intraconfigurational $4 \mathrm{f}-4 \mathrm{f}$ transitions, a broad emission band (called charge transfer band, CT)

\footnotetext{
* Prof. Dr. Janina Legendziewicz

University of Wrocław

Faculty of Chemistry

14 F. Joliot-Curie

PL-50-383 Wrocław/Poland

E-mail: j1@wchuwr.chem.uni.wroc.pl
}

1) Paper presented at the XVIII. Tage der Seltenen Erden (Terrae Rarae 2005), Bonn-Röttgen, 30.11.-2.12.2005. can be observed for the phosphate systems doped with trivalent ytterbium ions. In 1978, Nakazawa recorded the luminescence process from the charge transfer state (CT) for the $\mathrm{Yb}^{3+}$ ion in phosphate and oxysulfate lattices [11]. The $\mathrm{Yb}^{3+}$ ion's CT luminescence was also studied in others matrices [12]. Nevertheless, knowledge about the CT luminescence is still rather limited. It was reported that systems containing the $\mathrm{Lu}^{3+}$ ion instead of the $\mathrm{Y}^{3+}$ ion, co-doped with ytterbium, seem to be even a better lattice for the lasing performance [13].

This work is devoted to the structural and spectroscopic characteristics of new ytterbium doped sodium and rubidium lutetium double phosphates, $\mathrm{A}_{3} \mathrm{Lu}\left(\mathrm{PO}_{4}\right)_{2}: \mathrm{Yb}^{3+}$ $(\mathrm{A}=\mathrm{Na}, \mathrm{Rb})$. The results are compared with the analogous sodium and rubidium yttrium double phosphates which have already been reported in a previous paper [8].

\section{Experimental Section}

Double phosphates of the $\mathrm{A}_{3} \mathrm{Lu}\left(\mathrm{PO}_{4}\right)_{2}: \mathrm{Yb}^{3+}(\mathrm{A}=\mathrm{Na}, \mathrm{Rb})$ type were prepared by the procedure described in [7-10]. Samples with an of $\mathrm{Yb}^{3+}$ concentration of $10 \mathrm{~mol} \%$ were of good optical quality. The powder samples were analysed by X-ray diffraction (XRD) patterns recorded at room temperature for $2 \theta=1-120^{\circ}$ with a DRON-1 type diffractometer $\left(\mathrm{Cu}-\mathrm{K}_{\alpha}\right.$ radiation; $\left.\lambda=1,5418 \AA\right)$ and a Stoe Image Plate diffractometer (Universität zu Köln, Germany; Mo- $\mathrm{K}_{\alpha}$ radiation; $\lambda=0,7107 \AA$ ). The measurements confirm the formation of the appropriate double phosphate phases. The rubidium salts were found much more hygroscopic (because of their channel-like structure) than the sodium phosphates and had to be handled under dry conditions. Absorption spectra were measured with a Cary-Varian 500 scanning spectrophotometer equipped with an Oxford CF1204 helium flow cryostat between 4 and $293 \mathrm{~K}$ in 
the $850-1050 \mathrm{~nm}$ spectral region. The luminescence investigations were performed on a SUPERLUMI station at the HASYLAB (DESY, Hamburg, Germany). Synchrotron radiation in the VUV region was used for the excitation of the powder samples. The luminescence characteristics of the compounds under investigation were recorded at 10 and $293 \mathrm{~K}$ in a wide energy range $(80-1100 \mathrm{~nm})$.

\section{Results and Discussion}

Structures of double phosphates of the type $\mathrm{A}_{3} \mathrm{Y}\left(\mathrm{PO}_{4}\right)_{2}$ $(\mathrm{A}=\mathrm{Na}, \mathrm{K}, \mathrm{Rb})$ were investigated by several authors [1-6]. However, there is still only scarce knowledge about the structure of analogous compounds containing $\mathrm{Lu}^{3+}$ instead of $\mathrm{Y}^{3+}$. Melnikov reports on the structure of $\mathrm{Rb}_{3} \mathrm{Lu}\left(\mathrm{PO}_{4}\right)_{2}$ which is isostructural with $\mathrm{Rb}_{3} \mathrm{Y}_{(}\left(\mathrm{PO}_{4}\right)_{2}$ [5]. The compounds of the $\mathrm{A}_{3} \mathrm{Y}\left(\mathrm{PO}_{4}\right)_{2}$ family all have the same basic structure which is of the glaserite type. Depending
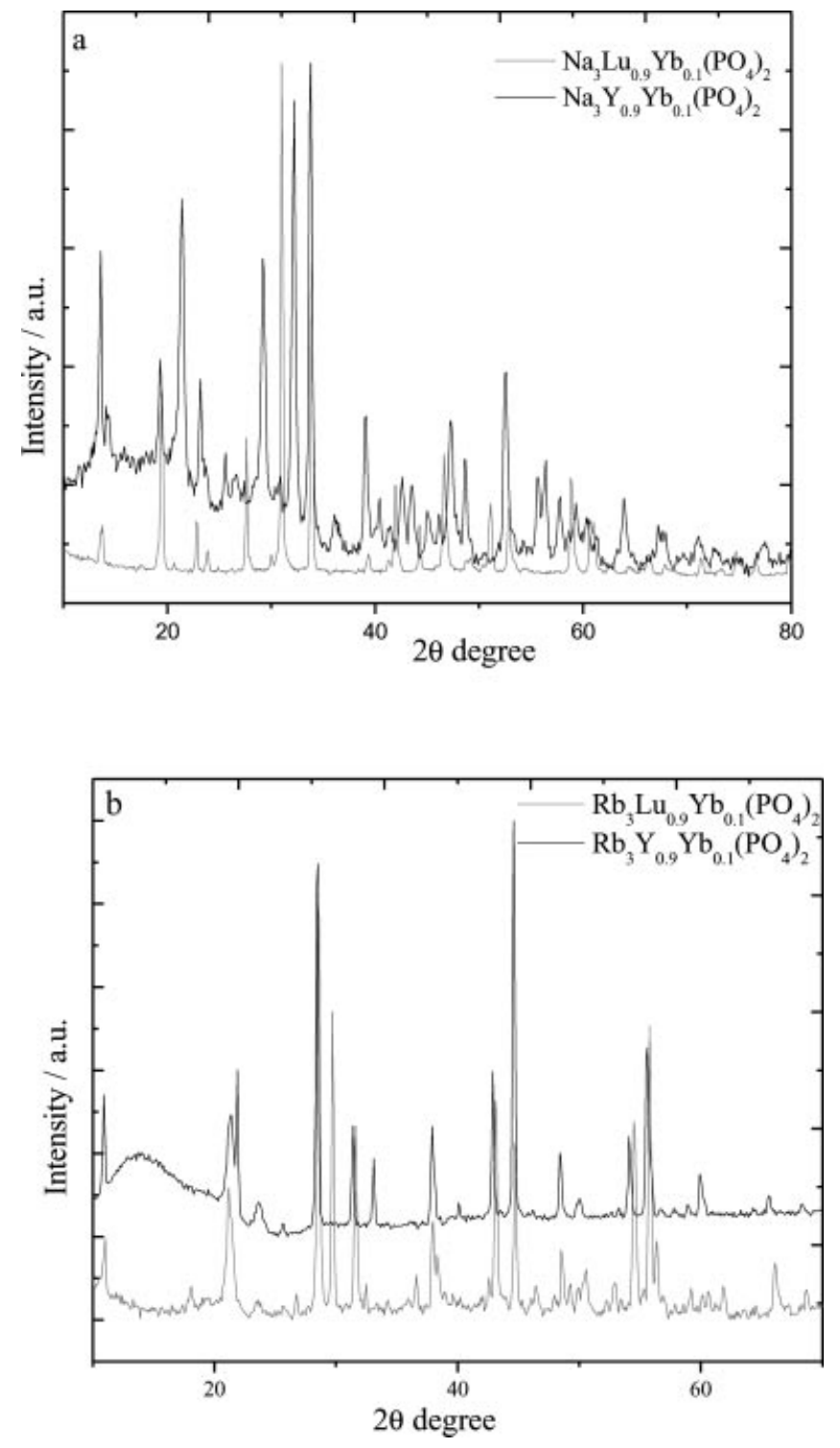

Fig. 1 XRD patterns of sodium (a) and rubidium (b) double phosphates powder samples. upon the alkali metal and the ionic radius of the lanthanide ion, the structures of these orthophosphates undergo a distortion. The rubidium phosphates crystallise with a hexagonal structure (space group R-3m, No. 164, $\mathrm{Z}=1$ ) from $\mathrm{Dy}$ to $\mathrm{Lu}$ and $\mathrm{Y}$ or with a monoclinic structure (space group $\mathrm{P} 2{ }_{1} / \mathrm{m}$, No. $11, \mathrm{Z}=2$ ) from $\mathrm{La}$ up to $\mathrm{Tb}[5,6]$. The sodium yttrium double phosphates crystallise in the orthorhombic system (space group $P b c 2_{1}$, No. 29, $Z=24$ ) $[3-5,7]$ which is a distortion variant of the hexagonal glaserite $\left(\mathrm{K}_{3} \mathrm{Na}\left(\mathrm{SO}_{4}\right)_{2}\right)$ type structure. It was expected that the lutetium double phosphates were isostructural with the yttrium double phosphates as it is observed for the orthophosphates, $\mathrm{YPO}_{4}$ and $\mathrm{LuPO}_{4}$, respectively, which have the same crystal structure, tetragonal, zircon-type. Fig. 1a shows the X-ray diffraction patterns of the sodium yttrium as well as lutetium double phosphates: The diffractograms are similar but not identical. Except for line shifts (typical because of the change of the ionic radius of the active ion) additional lines are observed. Thus, some structural modification of $\mathrm{Na}_{3} \mathrm{Lu}\left(\mathrm{PO}_{4}\right)_{2}$ may be suspected though its structure remains unknown so far. Diffractograms of the rubidium salts as presented in Fig. $1 \mathrm{~b}$ are much more similar which suggests that they have the same structure as the hexagonal rubidium yttrium double phosphates.

Absorption spectra at room and liquid helium temperatures show the ${ }^{2} \mathrm{~F}_{7 / 2} \rightarrow{ }^{2} \mathrm{~F}_{5 / 2}$ transition in absorption in the lutetium double phosphates similar to the analogous yttrium compounds as studied previously [9]. The f-f tran-

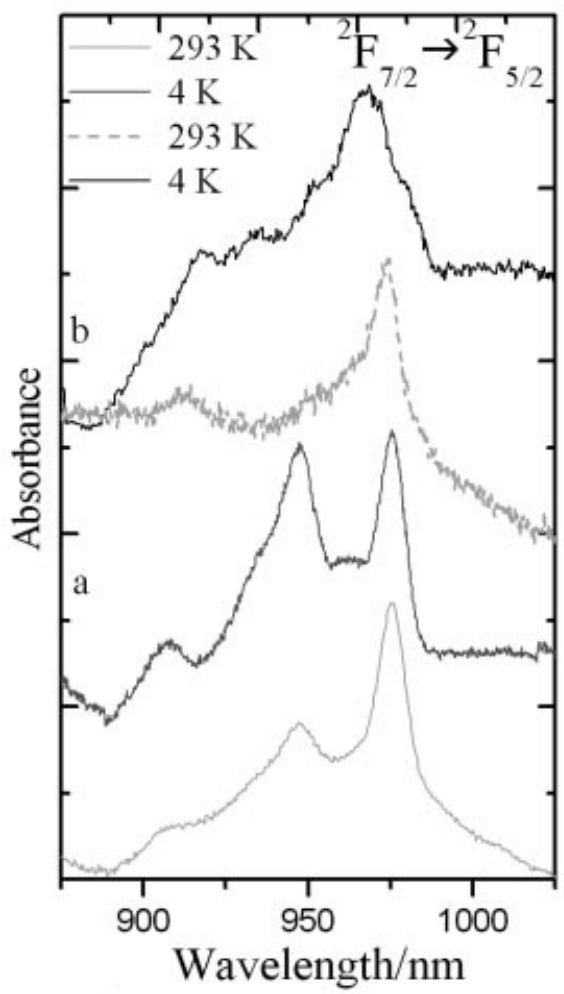

Fig. 2 Absorption spectra of $\mathrm{Na}_{3} \mathrm{Lu}_{0.9} \mathrm{Yb}_{0.1}\left(\mathrm{PO}_{4}\right)_{2}$ (a) and $\mathrm{Rb}_{3} \mathrm{Lu}_{0.9} \mathrm{Yb}_{0.1}\left(\mathrm{PO}_{4}\right)_{2}($ b) at 4 and $293 \mathrm{~K}$. 


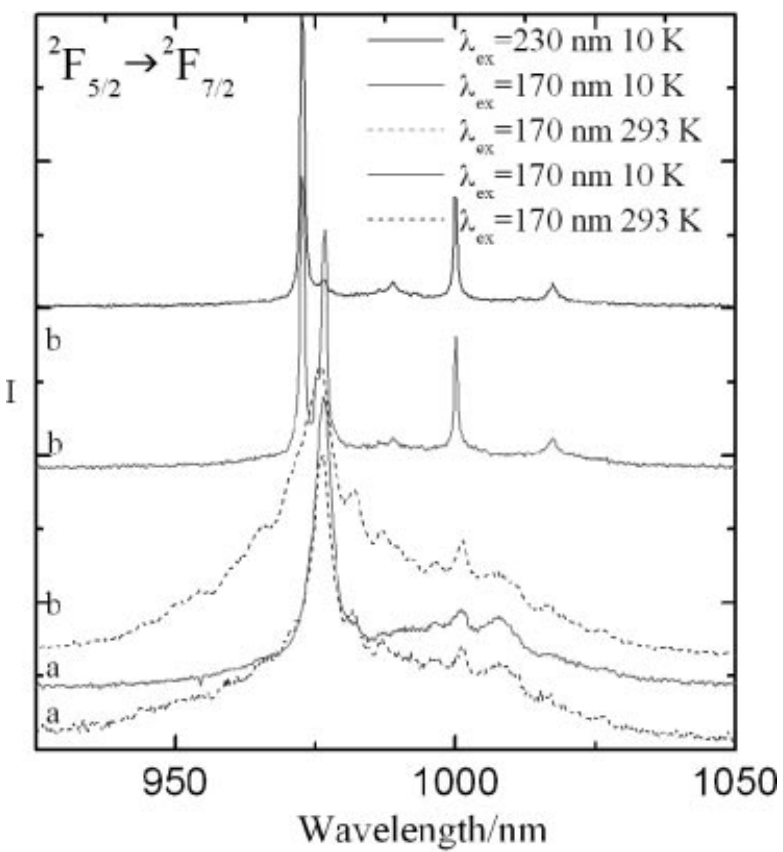

Fig. 3 Emission spectra of $\mathrm{Na}_{3} \mathrm{Lu}_{0.9} \mathrm{Yb}_{0.1}\left(\mathrm{PO}_{4}\right)_{2}$ (a) and $\mathrm{Rb}_{3} \mathrm{Lu}_{0.9} \mathrm{Yb}_{0.1}\left(\mathrm{PO}_{4}\right)_{2}$ (b) at 10 and $293 \mathrm{~K}$ under synchrotron radiation excitation with $\lambda_{\text {ex }}=170 \mathrm{~nm}$.

sition of $\mathrm{Yb}^{3+}$ is observed in the IR region. The bands in the absorption spectra of $\mathrm{Na}_{3} \mathrm{Lu}\left(\mathrm{PO}_{4}\right)_{2}: \mathrm{Yb}^{3+}$ consist of the main three electronic Stark components of the ${ }^{2} \mathrm{~F}_{5 / 2}$ excited level located at 10252, 10555 and $11008 \mathrm{~cm}^{-1}$. The total splitting of $756 \mathrm{~cm}^{-1}$ for $\mathrm{Na}_{3} \mathrm{Lu}\left(\mathrm{PO}_{4}\right)_{2}: \mathrm{Yb}^{3+}$ is a little smaller than that observed for the analogous yttrium salt $\left(801 \mathrm{~cm}^{-1}\right)$ [10].

The absorption of $\mathrm{Rb}_{3} \mathrm{Lu}\left(\mathrm{PO}_{4}\right)_{2}: \mathrm{Yb}^{3+}$ has only two marked bands with maxima at 10325 and $10899 \mathrm{~cm}^{-1}$. The third weak component can be distinguished at $10689 \mathrm{~cm}^{-1}$. Because three electronic Stark components are expected for the ${ }^{2} \mathrm{~F}_{5 / 2}$ excited state of $\mathrm{Yb}^{3+}$, the additional components observed in the spectra at $4 \mathrm{~K}$ can be due to the strong electron-phonon coupling and can be of vibronic and/or of cooperative origin. Some disorder of the structure can not be excluded. On the basis of the superposition of absorption, emission and FT-IR spectra (not presented here), the vibronic components at around 350, 480 and $690 \mathrm{~cm}^{-1}$ 0 -phonon lines were assigned [10]. The low-temperature absorption spectrum of the rubidium salt has a rather complex character because of the channel-like structure and expected distortion. Therefore, the interpretation of the spectra is not easy.

Typical emission spectra of ytterbium doped compounds are shown in Fig. 3. The spectra of the rubidium double phosphates demonstrate fine emission bands containing five explicit components. This result is surprising. In the case of the $\mathrm{Yb}^{3+}$ ion, one should observe transitions into four Stark components of the ground ${ }^{2} \mathrm{~F}_{7 / 2}$ split by the crystal field. The larger splitting of the ${ }^{2} \mathrm{~F}_{7 / 2}$ ground level caused

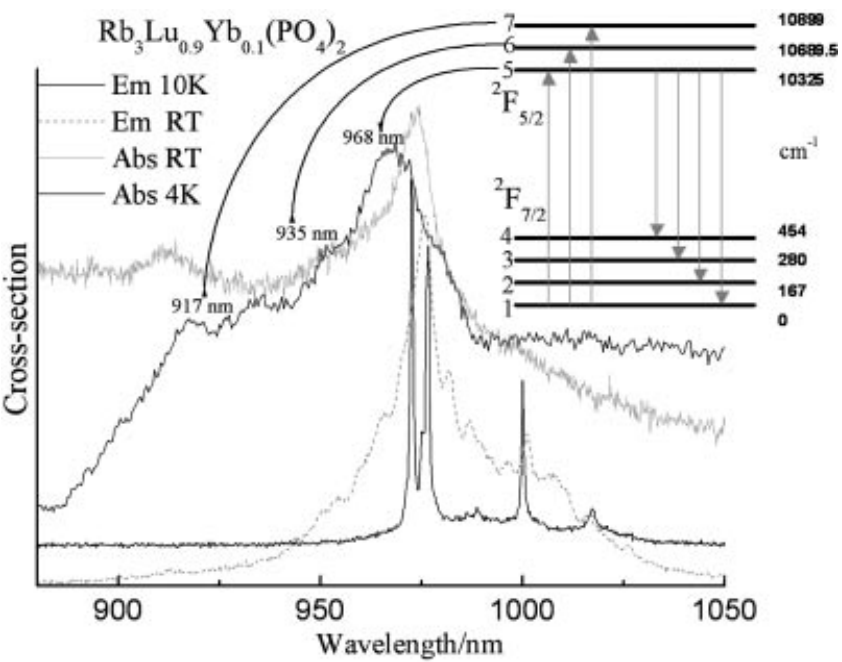

Fig. 4 Absorption and emission spectra of $\mathrm{Rb}_{3} \mathrm{Lu}_{0.9} \mathrm{Yb}_{0.1}\left(\mathrm{PO}_{4}\right)_{2}$ under synchrotron radiation, $\lambda_{\mathrm{ex}}=170 \mathrm{~nm}$, at low and room temperature.

by strong crystal field effects is manifested in the blue shift for $\mathrm{Rb}_{3} \mathrm{Lu}\left(\mathrm{PO}_{4}\right)_{2}: \mathrm{Yb}^{3+}$ when compared with $\mathrm{Na}_{3} \mathrm{Lu}\left(\mathrm{PO}_{4}\right)_{2}: \mathrm{Yb}^{3+}$. Additional weak components are the result of electron-phonon coupling with $\mathrm{M}-\mathrm{O}$ modes. Previous investigations of $\mathrm{Eu}^{3+}, \mathrm{Nd}^{3+}$ and $\mathrm{Pr}^{3+}$ doped double phosphates as sodium salts revealed that the active ions could occupy two or even more sites [8-9]. Similar as in the absorption spectra, the blue shift for lutetium double phosphates is also visible in the emission spectra. Based on absorption and emission spectra of the rubidium yttrium double phosphate an energy level scheme is proposed (Fig. 4).

Together with the $\mathrm{f}-\mathrm{f}$ transition of $\mathrm{Yb}^{3+}$, broad bands of allowed transitions from the charge transfer state in the high energy region were observed. From the luminescence spectra of the $\mathrm{Yb}^{3+}$ doped and undoped host lattices, it is easy to distinguish charge transfer luminescence of sodium double phosphates (Fig. 5). The investigated samples have an absorption edge at about $165 \mathrm{~nm}$. According to Jorgensen's expression, it is possible to estimate the position of the charge transfer transitions [14]. Using the optical electronegativities of $\mathrm{PO}_{4}{ }^{3-}$ and $\mathrm{Yb}^{3+}$, a transition at $220 \mathrm{~nm}$ would be expected. It is worth to notice that also double phosphates with a little bit larger ionic radius $\left(\mathrm{Y}^{3+}\right)$ exhibit CT luminescence [10]. For our double phosphates the charge transfer shifts towards a direction that does not correlate with data reported previously. It is known that CT emission shifts towards longer wavelengths when proceeding from $\mathrm{ScPO}_{4}$ to $\mathrm{YPO}_{4}$, just as the CT absorption bands [15]. This may be due to a strong distortion of the local environment of the $\mathrm{Yb}^{3+}$ ion. In contrast to the sodium salts, in the spectra of the rubidium double phosphates CT emissions were not detected. 


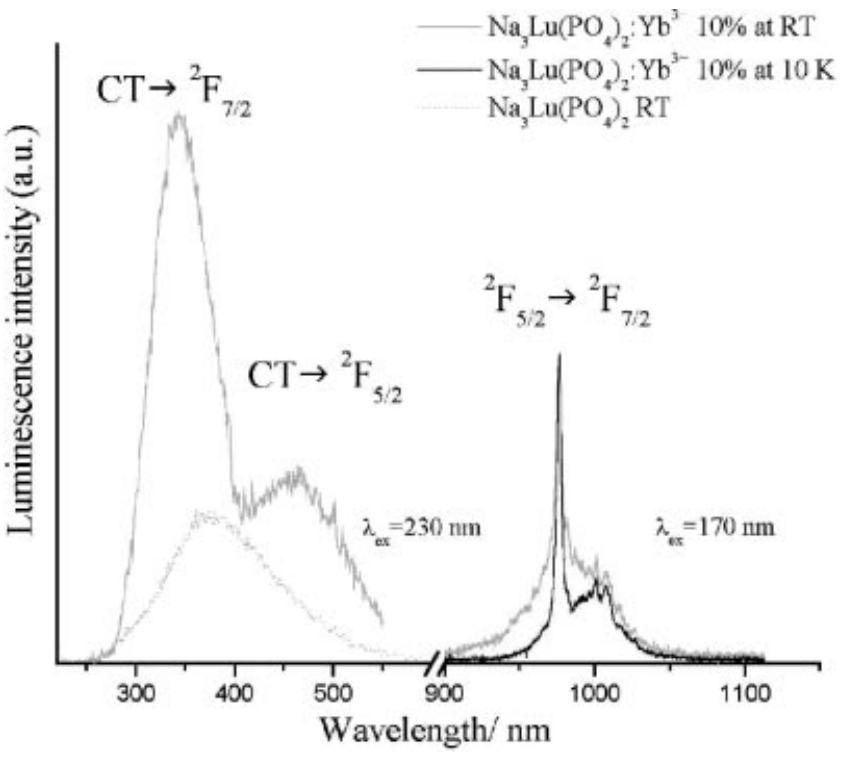

Fig. 5 Emission spectra of the $\mathrm{Na}_{3} \mathrm{Lu}\left(\mathrm{PO}_{4}\right)_{2}$ host lattice and of $\mathrm{Na}_{3} \mathrm{Lu}\left(\mathrm{PO}_{4}\right)_{2}$ doped with $10 \mathrm{~mol} \% \mathrm{Yb}^{3+}$, recorded at 10 and $293 \mathrm{~K}$ under synchrotron radiation excitation, $\lambda_{\mathrm{ex}}=170 \mathrm{~nm}$ and $\lambda_{\mathrm{ex}}=$ $230 \mathrm{~nm}$.

\section{Conclusions}

Using a solid state reaction route single-phase compounds of the $\mathrm{A}_{3} \mathrm{Lu}\left(\mathrm{PO}_{4}\right)_{2}(\mathrm{~A}=\mathrm{Na}, \mathrm{Rb})$ type were obtained. $\mathrm{X}$ ray powder diffraction shows that the rubidium yttrium and rubidium lutetium double phosphates are isotypic, while both types of sodium salts crystallize in different crystal structures. A comparison of the absorption spectra of the sodium lutetium double phosphates and the analogous rubidium salts display a blue shift of the latter compounds. Apart from the fundamental emission of $\mathrm{Yb}^{3+}$, a broad band luminescence origins from phosphate ligand to metal ion $\mathrm{CT}$ transition in $\mathrm{Na}_{3} \mathrm{Lu}\left(\mathrm{PO}_{4}\right)_{2}: \mathrm{Yb}^{3+}$ was observed while $\mathrm{Rb}_{3} \mathrm{Lu}\left(\mathrm{PO}_{4}\right)_{2}: \mathrm{Yb}^{3+}$ does not exhibit a charge transfer luminescence.

Acknowledgements. The authors wish to express gratitude to Prof. G. Meyer for help in the X-ray powder diffraction measurements. Experiments performed in HASYLAB DESY have been supported by the European Community (II-05-106 EC)..

[1] B. Finke, L. Schwarz, P. Günter, M. Kraas, M. Joppien, S. Becker, J. Lumin. 1994, 60/61, 975.

[2] L. Schwarz, B. Finke, M. Kloss, A. Rohmann, U. Sasum, D. Haberland, J. Lumin. 1997, 72-74, 257.

[3] Z. S. Chao, C. Perent, G. Le Flem, P. Hagenmuller, J. Solid State Chem. 1989, 82, 255.

[4] R. Salmon, C. Parent, M. Vlasse, G. Le Flem, Mater. Res. Bull. 1978, 13, 439.

[5] P. P. Melnikov, V. B. Kalinin, V. A. Efremov, L. N. Komisarowa, Izv. Akad. Nauk SSR. Neorg. Mater. 1981, 17, 1452.

[6] S. Areva, J. Hölsä, M. Kloss, M. Lahtinen, R.-J. Lamminmaki, M. Lastusaari, L. Schwarz, J. Valkonen, Mat.Sci.Forum 2001, 378-381, 644.

[7] M. Guzik, T. Aitasalo, W. Szuszkiewicz, J. Hölsä, B. Keller, J. Legendziewicz, J. Alloys Comp. 2004, 380, 368.

[8] W. Szuszkiewicz, B. Keller, M. Guzik, T. Aitasalo, J. Niittykoski, J. Hölsä, J. Legendziewicz, J. Alloys Comp. 2002, 341, 297.

[9] T. Aitasalo, M. Guzik, W. Szuszkiewicz, J. Hölsä, B. Keller, J. Legendziewicz, J. Alloys Comp. 2004, 380, 405.

[10] M. Guzik, J. Legendziewicz, W. Szuszkiewicz, A. Walasek, Opt. Mat., in press.

[11] E. Nakazawa, Chem. Phys. Lett. 1978, 56, 161.

[12] L. van Pieterson, M. Heeroma, E. de Heer, A. Meijerink, $J$. Lumin. 2000, 91, 177.

[13] A. Bensalah, Y. Guyot, A. Brenier, H. Sato, T. Fukuda, G. Boulon, J. Alloys Comp. 2004, 380, 15.

[14] C. K. Jørgensen, Prog. Inorg. Chem. 1970, 12, 161.

[15] L. van Pieterson, A. Meijerink, J. Alloys Comp. 2000, $300-301,426$. 